\title{
NÃO BASTA LER, É PRECISO COMPREENDER: UM ENFOQUE NA LEGIBILIDADE DO RESULTADO E DO EBITDA
}

\author{
IT IS NOT ENOUGH TO READ, WE HAVE TO UNDERSTAND: A FOCUS ON THE \\ READABILITY OF THE RESULT AND EBITDA
}

\section{NO BASTA CON LEER, HAY QUE COMPRENDER: UN ENFOQUE EN LA LEGIBILIDAD DEL RESULTADO Y DEL EBITDA}

Recebido em: 17-07-2019

Avaliado em: 12-05-2021

Reformulado em: 01-06-2021

Aceito para publicação em: 04-06-2021

Publicado em: 11-06-2021

Editor Responsável: Moacir M. Rodrigues Junior

\author{
Januário José Monteiro ${ }^{1}$ \\ Rodrigo Rengel ${ }^{2}$ \\ Allison Manoel de Sousa ${ }^{3}$ \\ Jose Alonso Borba ${ }^{4}$
}

\section{RESUMO}

As características das narrativas de legibilidade dos relatórios financeiros podem gerar interpretações dúbias, potencializando e/ou distorcendo a informação sobre a realidade econômica da companhia. Redigir parágrafos ou sentenças curtas/longas, com palavras difíceis/simples ou com a utilização de termos de transição nos relatórios apresentados ao público externo é uma forma de ofuscar a mensagem. Este estudo objetiva analisar a influência do desempenho econômico-financeiro na legibilidade das narrativas textuais dos trechos do resultado líquido e EBITDA. Trata-se de uma pesquisa quanti-quali, operacionalizada por meio da técnica estatística de dados em painel e análise de conteúdo. Para isso, analisou-se no Relatório da Administração (RA), informações a respeito do resultado líquido, EBITDA e mensagem da administração. Descobriu-se que algumas empresas mudaram o enfoque dos trechos quando houve prejuízo no período. Mas, ao olhar a análise quantitativa, verifica-se que isso não é um comportamento generalizado, pois, em média, empresas que registraram lucro no período não apresentaram mudanças significativas no nível de legibilidade do resultado líquido. A mensagem da administração de cunho positivo acerca do desempenho do período tem reflexos no aumento da legibilidade do EBITDA, mas não está associada à legibilidade do resultado líquido. As variações percentuais do resultado líquido e do EBITDA não estão relacionadas com a legibilidade desses dois indicadores, respectivamente. Esses achados podem auxiliar os investidores a identificarem gatilhos que influenciam na legibilidade do resultado líquido e do EBITDA e, consequentemente, nas decisões de investimentos.

Palavras-chave: Legibilidade; Resultado Líquido; EBITDA; Relatório da Administração.

\footnotetext{
${ }^{1}$ Doutorando no Programa de Pós-Graduação em Contabilidade (PPGC) da Universidade Federal de Santa Catarina (UFSC), Brasil; E-mail: januariomonteiromonteiro@gmail.com

${ }^{2}$ Doutorando no Programa de Pós-Graduação em Contabilidade (PPGC) da Universidade Federal de Santa Catarina (UFSC), Brasil; E-mail: rengel.rodrigo@hotmail.com

${ }^{3}$ Doutorando no Programa de Pós-Graduação em Contabilidade (PPGCONT) da Universidade Federal do Paraná (UFPR), Brasil; E-mail: allison.msousa@gmail.com

${ }^{4}$ Doutor em Contabilidade e Controladoria pela Universidade de São Paulo (USP); Professor no Programa de PósGraduação em Contabilidade (PPGC) da Universidade Federal de Santa Catarina (UFSC), Brasil; E-mail: j.alonso@ufsc.br
} 


\section{ABSTRACT}

The characteristics of the financial reports' readability narratives can generate dubious interpretations, enhancing and/or distorting information about the company's economic reality. Writing short/long paragraphs or sentences, using difficult/simple words, or using transitional terms in the reports presented to the external public is a way of obfuscating the message. This study aims to analyze the influence of economic-financial performance on the legibility of the textual narratives of the excerpts of net result and EBITDA. It is quantitative-qualitative research, operationalized through the statistical technique of panel data and content analysis. We analyzed in the Management Report (RA) information regarding the net result, EBITDA, and message from the management. We found that some companies changed the focus of the stretches when there was a loss in the period. However, when looking at the quantitative analysis, we see that this is not a generalized behavior. This is because, on average, companies that recorded profits in the period do not show significant changes in the level of readability of the net result. The positive message from management about the period's performance is reflected in the increase in the readability of EBITDA. However, it is not associated with the readability of the net result. The percentage changes in net income and EBITDA are not related to the readability of net income and EBITDA, respectively. These findings can help investors to identify triggers that influence the readability of net income and EBITDA, and consequently, in investment decisions.

Keywords: Legibility; Net income; EBITDA; Management report.

\section{RESUMEN}

Las características de las narrativas de legibilidad de los informes financieros pueden generar interpretaciones dudosas, mejorando y / o distorsionando información sobre la realidad económica de la empresa. Escribir párrafos u oraciones cortos / largos, usar palabras difíciles / simples o usar términos de transición en informes presentados a audiencias externas es una forma de eclipsar el mensaje. Este estudio tiene como objetivo analizar la influencia del desempeño económico-financiero en las narrativas textuales de extractos de resultado neto y EBITDA. Es una investigación cuantitativa-cualitativa, operacionalizada a través de la técnica estadística de datos de panel y análisis de contenido. Para ello, analizamos en el Informe de Gestión (RA), información sobre el resultado neto, EBITDA y mensaje de la dirección. Descubrimos que algunas empresas cambiaron el enfoque de los tramos cuando hubo una pérdida en el período. Pero cuando miramos el análisis cuantitativo, vemos que este no es un comportamiento generalizado. Esto se debe a que, en promedio, las empresas que registraron beneficios en el período no muestran cambios significativos en el nivel de legibilidad del resultado neto. El mensaje positivo de la gerencia sobre el desempeño del período se refleja en el aumento en la legibilidad del EBITDA, pero no está asociado con la legibilidad del resultado neto. Los cambios porcentuales en la utilidad neta y el EBITDA no están relacionados con la legibilidad de la utilidad neta y el EBITDA, respectivamente. Estos hallazgos pueden ayudar a los inversores a identificar los factores desencadenantes que influyen en la legibilidad de la utilidad neta y el EBITDA y, en consecuencia, en las decisiones de inversión.

Palabras-clave: Legibilidad; Resultado líquido; EBITDA; Informe de la Administración.

\section{INTRODUÇÃO}

A legibilidade dos relatórios financeiros é uma característica essencial para que os usuários externos possam compreender, da melhor forma, as informações apresentadas pelas companhias. Assim, podem tomar decisões assertivas, dado que a complexidade das informações exige maior tempo, esforço e pode comprometer a análise dos investidores (Bloomfield, 2002). Estudos sobre esse tópico indicam que a legibilidade dos relatórios financeiros está condicionada ao desempenho da 
NÃO BASTA LER, É PRECISO COMPREENDER: UM ENFOQUE NA LEGIBILIDADE DO RESULTADO E DO EBITDA

organização e aos interesses dos gestores, como os Chief Executive Officers (CEOs) e Chief Financial Officers (CFOs) (Dempsey, Harrison, Luchtenberg, \& Seiler, 2012; Laksmana, Tietz, \& Yang, 2012; Lee, 2012).

Nessa circunstância, ao considerar as diferentes medidas apresentadas na literatura contábil quanto ao desempenho das companhias, tem-se o Earnings Before Interest Taxes Depreciation and Amortization (EBITDA), tido como uma medida de desempenho operacional. Este indicador mensura a eficiência das operações e oferece uma imagem clara sobre o desempenho operacional da organização, já que não considera as despesas financeiras e não desembolsáveis, como a depreciação/amortização (Greenberg, 1998; Vasconcelos, 2001). Logo, compreender como as organizações divulgam as informações sobre o EBITDA torna-se importante.

$\mathrm{Li}$ (2010) argumenta que narrativas textuais não estruturadas ou que ocultam informações nos relatórios financeiros podem levar a irregularidades, ambiguidades e oportunismo gerencial. As divulgações complexas de informações de difícil entendimento, que levam a relatórios anuais menos legíveis, são prejudiciais às partes interessadas no que concerne à capacidade de processar informações, o que afeta a maneira como emitem seus julgamentos e tomam decisões (Li, 2008; You \& Zhang, 2009; Miller, 2010). Dempsey et al. (2012) examinaram o grau de legibilidade das informações contábeis relacionadas ao retorno sobre o ativo (ROA). Os achados evidenciaram que quanto menor o ROA, menos legível eram as informações contábeis relacionadas a este indicador.

De acordo com Inger, Meckfessel, Zhou, \& Fan (2018), os gerentes geralmente buscam divulgar informações úteis para aumentar a qualidade da tomada de decisão das partes interessadas. Contudo, eles possuem prerrogativas para destacar informações tidas como "boas" ao obterem melhores desempenhos, ou ocultar informações ao não ter o desempenho desejado ou ter prejuízo. Já a pesquisa de Asay, Elliott e Rennekamp (2017) sugere que os investidores podem se utilizar de fontes de informações externas e ser influenciados caso as divulgações das empresas sejam menos legíveis, limitando os benefícios idealizados por gestores. Os gerentes têm discrição quanto ao conteúdo enfatizado, idioma e estilo de escrita usados durante a narrativa das demonstrações (Loughran \& Mcdonald, 2014; Henry \& Leone, 2016).

A literatura que aborda sobre a legibilidade é abrangente. De um lado, avalia a legibilidade dos relatórios financeiros e a forma como estes são divulgados (Smith \& Smith, 1971; Healy, 1977; Lebar, 1982; Jones \& Shoemaker, 1994; Lim, Chalmers, \& Hanlon, 2018). De outro, investiga como o estilo de liderança, características de cada gerente e empresa pode afetar na forma como os relatórios são divulgados e, por consequência, na legibilidade dos relatórios financeiros (Law \& Mills, 2015; Lim et al., 2018), desempenho organizacional, lucratividade, persistência dos lucros (Li, 2008; Cazier \& Pfeiffer, 2016) e no gerenciamento de resultados (Lo, Ramos, \& Rogo, 2017). Um outro corpo da literatura tratou sobre a legibilidade de maneira específica, ao analisar o conteúdo de notas explicativas referente a tributos (Inger, 2014; Simone, Mills, \& Stomber, 2014; Inger et al., 2018).

Apesar dos estudos terem usado diversas medidas de desempenho para atestar a legibilidade dos relatórios financeiros, não se atentaram em investigar narrativas textuais de itens do desempenho das operações das empresas, como o EBITDA. Além disso, Merkl-Davies e Brennan (2007), Li (2010) e Souza, Rissatti, Rover e Borba (2019) sugerem pesquisas futuras que tratem dessa temática de maneira mais aprofundada e em ambientes onde os relatórios financeiros não sejam apresentados em língua inglesa. Isso gerou insights para a presente pesquisa, no sentido de desenvolver um estudo que envolvesse tanto a análise quantitativa, quanto a qualitativa, em um ambiente organizacional no qual as empresas divulgam seus relatórios na língua portuguesa.

Gomes, Ferreira e Martins (2018) também entendem que se faz necessário estudos que analisem o conteúdo informacional dos relatórios financeiros, sobretudo, de uma forma mais aprofundada, por meio de uma análise qualitativa. Dentre esses relatórios, Kos, Espejo e Raifur (2014) destacam o Relatório de Administração (RA), uma vez que apresenta informações importantes sobre a empresa, o que pode auxiliar o processo decisório dos usuários externos, além de ser desenvolvido conforme o desempenho alcançado no exercício. Além disso, os autores destacam que 
é importante os enfoques informacionais contidos no RA. A partir dessas discussões, este estudo se pautou em analisar a influência do desempenho econômico-financeiro na legibilidade das narrativas textuais dos trechos de resultado líquido e EBITDA.

O presente estudo é importante e original ao se debruçar a respeito das narrativas textuais relacionadas ao EBITDA, e ao incluir uma análise qualitativa das divulgações da alta administração sobre o decorrer do exercício econômico. Isso traz uma ótica complementar, que pode contribuir na academia e na prática, visto que, até o momento, as pesquisas se atentaram somente à legibilidade do resultado líquido. Observa-se ainda a viabilidade da pesquisa, em virtude da disponibilidade de acesso aos dados, uma vez que estes são disponibilizados para consulta do público em geral, por meio do site da Comissão de Valores Mobiliários (CVM).

Este estudo se justifica e demonstra contribuições teóricas ao tratar a relação entre as narrativas textuais e o desempenho financeiro, investigados em pesquisas como as de Subramanian, Insley e Blackwell (1993), Asay et al. (2017), Kim, Wang e Zhang (2019) e Souza et al. (2019). De modo complementar, agrega-se à literatura sobre oportunismo gerencial e sugere-se que o parecer da alta administração, no item mensagem da administração, pode ocasionar desvio de atenção dos usuários externos, sobretudo os investidores, no que concerne ao desempenho financeiro da companhia.

Dentre os principais resultados e contribuições da pesquisa, têm-se evidências que demonstram que ao reportar resultado líquido positivo no período, as narrativas apresentadas pelas empresas não apresentam reflexos significativos na legibilidade deste resultado líquido no RA. Há, também, inexistência de mudança significativa no nível de legibilidade do resultado líquido, quando relacionada à variação do resultado líquido do período em comparação ao ano anterior. A legibilidade do resultado líquido também não é suscetível a alterações significativas no momento em que a administração faz referências positivas sobre o desempenho do período. Isso mostra que no Brasil, em média, tais fatores não impactam na legibilidade do resultado líquido, o que complementa os estudos de Kim et al. (2019) e Souza et al. (2019).

Este resultado pode ser considerado como benéfico aos investidores, uma vez que a legibilidade do resultado líquido, referente aos trechos do RA, não é afetada pelo desempenho. Com isso, mesmo em períodos em que a companhia apresentou resultado líquido negativo ou inexistência de menção positiva da administração sobre o desempenho do período, não houve ofuscação nas narrativas. Assim, os investidores não precisam buscar informações adicionais para suprir os dados ofuscados pelos gestores.

A respeito da legibilidade do EBITDA, os resultados indicam que há aumento no momento em que a administração faz menções positivas sobre o desempenho do período. Isso mostra uma nova faceta sobre o tema, em especial, aos trabalhos que também abordaram a temática, como Subramanian et al. (1993), Asay et al. (2017), Kim et al. (2019) e Souza et al. (2019), já que os trechos sobre o EBITDA sofrem influência dos gestores, ao se tornar mais ou menos legíveis em algumas situações. Em termos práticos, contribui-se aos investidores ao elucidar que os gestores ofuscam os trechos sobre o EBITDA quando não fazem menções positivas sobre o desempenho. Essa ação dos gestores pode ser prejudicial à tomada de decisão, pois pode induzir os investidores a interpretarem a situação econômico-financeira da companhia incorretamente. Além disso, pode induzi-los a procurar outras informações que podem ter custos adicionais para tomar decisões mais assertivas a respeito da alocação de recursos financeiros em investimentos.

\section{REFERENCIAL TEÓRICO}

A Teoria da Informação preocupa-se com a efetividade da mensagem transmitida por meio do processo de comunicação (Araújo, 2009). Desenvolvida por Shannon e Weaver em 1948, foca em três níveis de problemas: (i) problemas técnicos para o transporte da informação; (ii) problemas semânticos, ou seja, os significados das palavras; e (iii) problemas pragmáticos, os quais estão 
relacionados com a eficácia da informação. Neste caso, o transmissor deseja causar no receptor determinado comportamento ou reação. Este estudo volta-se para o terceiro ponto abordado pela teoria.

$\mathrm{Na}$ literatura contábil, as formas de divulgação das informações econômicas e financeiras, em geral, têm sido objeto de discussão. Kim et al. (2019) apontam que essas narrativas podem ser divulgadas de maneira complexa pelos gerentes, na tentativa de distorcerem ou ofuscarem informações. Li (2010) trata de irregularidades, ambiguidades e oportunismo gerencial caso as narrativas textuais não estejam estruturadas ou ocultem informações nos relatórios contábeis. A divulgação de informações de difícil entendimento tornam os relatórios menos legíveis, prejudicando o processamento das informações pelos usuários externos da informação contábil (Li, 2008; You \& Zhang, 2009; Miller, 2010).

Em busca deste elo entre a corrente teórica da Teoria da Informação e aplicação contábil, o RA se mostrou o mais adequado para tal análise. Isso porque contempla o desempenho organizacional por meio de uma linguagem com menor rigor técnico, e por ser o espaço oficial para comunicados da organização a respeito do desempenho obtido no exercício. De acordo com Doná, Marques, Moribe, \& Hercos Jr. (2016), esta é uma possível razão para a qual o RA possa atingir uma quantia maior de usuários. Dentre eles, destacam-se os investidores (Hendriksen \& Van Breda, 2007).

Embora o RA seja um documento da administração, previsto no artigo 133 da Lei n. ${ }^{\circ}$ 6.404/76 e com regulação da CVM, cujo Parecer de Orientação 15 (1987) alerta para a importância de divulgar informações úteis, fidedignas e detalhadas aos usuários, bem como a omissão de informações e dados genéricos vão contra aos interesses e direitos dos investidores. Estudos apontam possíveis manipulações em suas divulgações. Dye (2001) relata que as empresas seguem as premissas da Teoria da Divulgação Voluntária, em que apenas informações em cenários favoráveis são apresentadas, optando por omiti-las em casos prejudiciais. Inger et al. (2018), por outro lado, possuem uma visão contrária, pois compreendem que os gestores costumam repassar informações úteis aos seus usuários por vislumbrar uma melhor tomada de decisão. Mas para isso, as informações apresentadas aos usuários externos devem ser dotadas de confiabilidade e estarem livres de erros (Colauto \& Marques, 2010).

A literatura tem apresentado diferentes análises e resultados ao tratar da legibilidade em relatórios contábeis. Subramanian et al. (1993), ao analisarem a relação entre a legibilidade dos relatórios financeiros com o desempenho financeiro, perceberam que quando as empresas apresentavam resultados satisfatórios sobre o desempenho do período, havia aumento na legibilidade. Pode-se observar que estudos similares que trataram da legibilidade referente ao lucro, em alguns momentos, também tangenciam outros trechos dos relatórios. Por exemplo, informações acerca do risco (agências de rating), custo da dívida, ambiguidades das informações financeiras, estratégias empresariais, entre outros (Bonsall \& Miller, 2017; Ertugrul, Lei, Qiu, \& Wan, 2017; Kim et al., 2019; Habib \& Hasan, 2018; Tschopp, Barney, \& Dean, 2018; Xu, Fernando, \& Tam, 2018).

Bonsall e Miller (2017) examinaram o impacto da legibilidade dos relatórios financeiros nas classificações das agências de risco (rating). Os resultados demonstraram que as divulgações financeiras menos legíveis estavam associadas a piores classificações das agências de risco e a um maior custo da dívida. Ertugrul et al. (2017) investigaram o impacto da legibilidade dos relatórios financeiros anuais nas ambiguidades das narrativas sobre o custo do empréstimo. Os achados evidenciaram que a legibilidade e a ambiguidade das demonstrações financeiras estavam associadas à acumulação de informações gerenciais. Nesse sentido, acionistas de empresas com relatórios menos legíveis e mais ambíguos são prejudicados por conta da falta de transparência nos relatórios e acabam suportando maiores custos de financiamento.

Kim et al. (2019) observaram que os gerentes podem ocultar diversas informações por meio da elaboração de relatórios financeiros complexos. Desse modo, o efeito da complexidade do relatório financeiro é mais enfatizado por empresa com resultado negativo. Habib e Hasan (2018) investigaram a associação entre a estratégia de negócios e a legibilidade de suas narrativas nos relatórios anuais. $\mathrm{O}$ 
desfecho da pesquisa aponta que empresas com estratégias prospectoras produzem narrativas menos legíveis do que aquelas com estratégias defensoras. Foi ainda observada que a relação entre as estratégias e a legibilidade era parcialmente mediada pelo desempenho organizacional.

Tschopp et al. (2018) analisaram a legibilidade das notas explicativas de 30 empresas listadas na Bolsa de Nova Iorque, nos Estados Unidos da América (EUA), durante alguns anos da década de 2000, bem como no período entre 2010 e 2015. Eles demonstraram que, à medida em que o tempo passa, a legibilidade diminui. Além disso, descobriram a predominância do uso da voz passiva nos relatórios. Xu et al. (2018) examinaram a legibilidade dos relatórios em relação à idade do CEO, baseados na Teoria do Alto Escalão. Os resultados apontaram que CEOs mais antigos tendiam a ser mais éticos e divulgavam relatórios mais legíveis.

A legibilidade também se tornou objeto de estudos nacionais. Souza e Silva (2016) observaram 311 empresas listadas na B3, por meio de uma análise de conteúdo. Eles apontaram que mais de 70\% dos RA de 2009 não tiveram alterações significativas, comparados a 2008. Miranda, Reina e Lemes (2018) apontaram para uma diminuição do grau de complexidade dos relatórios a partir do ano de 2005 até 2016. Sugerem, ainda, uma possível ligação dos achados com o período posterior a adoção da International Financial Reporting Standards (IFRS).

Em relação ao EBITDA, embora seja um indicador importante para as organizações, é pouco abordado na literatura. Por exemplo, Frezatti e Aguiar (2007) ressaltam que os clássicos em finanças e contabilidade dificilmente fazem referência ao mesmo. Contudo, é um indicador que demonstra sua relevância, por expressar de forma clara o resultado operacional, e por ser uma medida mais próxima que traduz o caixa operacional gerado no período, o que permite que as decisões sejam tomadas de maneira mais assertiva. Eastman (1996) destaca que é o indicador favorito dos analistas e uma das medidas mais populares. Dada a relevância desse indicador, torna-se indispensável entender como as empresas divulgam suas narrativas nos relatórios financeiros, visto que, como afirma Malvessi (2006), instituições financeiras, investidores e analistas utilizam frequentemente essa medida para tomarem decisões e realizarem comparações entre empresas.

\section{PROCEDIMENTOS METODOLÓGICOS}

A população do estudo consistiu nas 100 maiores companhias do Novo Mercado da B3 (ao considerar a listagem de 2018), de acordo com o valor do ativo total das demonstrações consolidadas, no quarto trimestre de 2017. Esse grupo de companhias, de acordo com a B3 (2018), é dotado de organizações que tendem a ser mais transparentes. Como critério de seleção, não foram consideradas as empresas financeiras (que atuam no subsetor de intermediários financeiros, previdência e seguros, securitizadoras de recebíveis, serviços financeiros diversos, conforme classificação da B3). Isso porque as companhias financeiras estão sob jugo de legislações específicas, além de ter operações diferenciadas em relação às companhias dos demais setores que compõem o Novo Mercado. $\mathrm{O}$ intervalo de análise foi de períodos anuais de 2015 a 2017, já que o RA, utilizado como base para calcular a legibilidade do resultado líquido e do EBITDA, é publicado apenas ao fim de cada exercício econômico.

Quanto aos procedimentos de coleta de dados, foi realizada a consulta nos RA a partir do site da CVM. Por meio desses relatórios, coletou-se as narrativas do resultado líquido e do EBITDA da companhia. Do mesmo modo, foram coletadas as narrativas referentes ao desempenho financeiro da companhia escrita pelo(a) presidente/diretoria/conselho de administração, possibilitando, assim, averiguar o posicionamento da alta administração. Já os dados econômico-financeiros foram coletados da base de dados Economatica®.

Das 100 empresas com o maior porte, apenas 62 companhias tinham dados disponíveis para a análise, totalizando 157 observações. Utilizou-se o modelo de regressão linear múltipla para atingir o objetivo desta pesquisa. Por se basear na média, observações discrepantes podem distorcer os resultados e, desse modo, causar interpretações incorretas por parte dos pesquisadores. Por esse 
motivo, os dados foram submetidos ao teste de Hadi (1992), com o propósito de identificar se há a existência de outliers. Esse teste classificou 21 observações como dados discrepantes, das quais, duas companhias tiveram todos os dados classificados como outliers. Devido à capacidade de provocar vieses à análise, optou-se por excluir os dados discrepantes da amostra. Com isso, a amostra final foi composta por 138 observações, correspondentes a 60 empresas.

Após a coleta dos dados necessários para a pesquisa, realizou-se a análise de conteúdo das narrativas do RA. As técnicas de análise de conteúdo compreendem 3 etapas: (a) pré-análise; (b) exploração do material e; (c) tratamento dos resultados (Bardin, 1995). Na primeira etapa, efetuou-se a seleção das empresas, dos períodos que compreendem os dados coletados e os documentos que a análise tomou por base. Na segunda etapa, realizou-se a leitura e interpretação dos relatórios financeiros, especificamente nos itens necessários para o desenvolvimento do presente estudo, que foram categorizados por: (i) narrativas sobre resultado líquido; (ii) EBITDA; e (iii) mensagem da alta administração ou mensagem do CEO. Por fim, na terceira etapa, elaborou-se as amarrações necessárias entre as categorias de análise.

Em momento posterior à coleta e análise das narrativas textuais, procedeu-se ao cálculo da legibilidade das narrativas do resultado líquido e do EBITDA, além da classificação das narrativas sobre o desempenho financeiro da empresa pela alta administração. Para mensurar a legibilidade, recorreu-se ao método de Flesch (1948). A ferramenta utilizada para calcular a legibilidade foi o Microsoft Word 2007, atestada de confiabilidade e utilizada em estudos que capturam a legibilidade de relatórios financeiros, ver Williamson e Martin (2010).

$$
\text { LEGIBILIDADE }_{i t}=206,835-1,015\left(\frac{\text { Total de Palavras }_{i t}}{\text { Total de Sentenças }_{i t}}\right)-84,6\left(\frac{\text { Total de Silabas }_{i t}}{\text { Total de Palavras }_{i t}}\right)
$$

Em que: LEGIBILIDADE $_{\text {it }}=$ legibilidade mensurado pelo método Flesch da empresa i do período t; Total de Palavras ${ }_{i t}=$ número palavras no trecho da empresa i do período t; Total de Sentenças ${ }_{i t}=$ número de sentenças no trecho da empresa $\mathrm{i}$ do período t, e; Total de Sílabas ${ }_{i t}=$ total de silabas na sentença da empresa i do período t.

Tabela 1

Variáveis que compõem o estudo

\begin{tabular}{|c|c|c|c|}
\hline \multicolumn{4}{|c|}{ Variáveis Dependentes } \\
\hline Variável & Descrição & Operacionalização & Referências \\
\hline $\begin{array}{l}\text { Legibilidade do } \\
\text { Resultado Líquido } \\
\text { (LEGRE) }\end{array}$ & $\begin{array}{c}\text { Variável que mede a } \\
\text { legibilidade do Resultado } \\
\text { Líquido }\end{array}$ & $\begin{array}{c}\text { LEGRE }=206,835-1,015 \\
((\text { Total de Palavras }) /(\text { Total de } \\
\text { Sentenças }))-84,6((\text { Total de } \\
\text { Sílabas }) /(\text { Total de Palavras }))\end{array}$ & \multirow{2}{*}{$\begin{array}{l}\text { Subramanian et al. } \\
\text { (1993); Dempsey et } \\
\text { al. (2012); Laksmana } \\
\text { et al. (2012); Lo et al. } \\
\text { (2017) }\end{array}$} \\
\hline $\begin{array}{l}\text { Legibilidade do EBITDA } \\
\text { (LEGEBITDA) }\end{array}$ & $\begin{array}{l}\text { Variável que mede a } \\
\text { legibilidade do EBITDA }\end{array}$ & $\begin{array}{l}\text { LEGEBITDA = 206,835-1,015 } \\
\text { ((Total de Palavras)/(Total de } \\
\text { Sentenças))-84,6 ((Total de } \\
\text { Sílabas)/(Total de Palavras) })\end{array}$ & \\
\hline \multicolumn{4}{|c|}{ Variáveis Independentes } \\
\hline Variável & Descrição & Operacionalização & Referências \\
\hline $\begin{array}{l}\text { Resultado Líquido } \\
\text { Positivo } \\
\text { (RESULPOSITIVO) }\end{array}$ & $\begin{array}{l}\text { Tem como finalidade medir os } \\
\text { períodos em que houve } \\
\text { resultado líquido positivo }\end{array}$ & $\begin{array}{c}\text { Variável dummy com duas } \\
\text { categorias: exercício contábil } \\
\text { onde houve lucro (1) exercício } \\
\text { contábil onde houve prejuízo } \\
(0) .\end{array}$ & $\begin{array}{l}\text { Subramanian et al. } \\
\text { (1993); Kim et al. } \\
(2019) ; \text { Souza et al. } \\
(2019) \text {. }\end{array}$ \\
\hline
\end{tabular}




\begin{tabular}{|c|c|c|c|}
\hline $\begin{array}{l}\text { Variação Percentual do } \\
\text { Resultado Líquido } \\
\text { ( } \Delta \% \text { RESUL })\end{array}$ & $\begin{array}{l}\text { Tem como objetivo verificar a } \\
\text { variação percentual do } \\
\text { resultado líquido referente ao } \\
\text { exercício atual em relação ao } \\
\text { resultado líquido do período } \\
\text { anterior }\end{array}$ & $\begin{array}{c}\text { ((Resultado Líquido }{ }_{\text {it }} / \\
\left.\text { Resultado Líquido }_{\text {it-1 }-1)}\right) * 100\end{array}$ & $\begin{array}{l}\text { Subramanian et al. } \\
\text { (1993); Kim et al. } \\
\text { (2019); Souza et al. } \\
\text { (2019). }\end{array}$ \\
\hline $\begin{array}{l}\text { Variação Percentual do } \\
\text { EBITDA ( } \Delta \% \text { EBITDA) }\end{array}$ & $\begin{array}{l}\text { Tem como objetivo verificar a } \\
\text { variação percentual do } \\
\text { EBITDA referente ao exercício } \\
\text { atual em relação ao EBITDA } \\
\text { do período anterior }\end{array}$ & $\begin{array}{c}\left(\left(\mathrm{EBITDA}_{\mathrm{it}} / \mathrm{EBITDA}_{\mathrm{it}-1}\right)-\right. \\
1)^{* 100}\end{array}$ & $\begin{array}{l}\text { Subramanian et al. } \\
\text { (1993); Kim et al. } \\
\text { (2019). }\end{array}$ \\
\hline $\begin{array}{c}\text { Mensagem Positiva da } \\
\text { Administração sobre o } \\
\text { desempenho } \\
\text { (ADMPOSITIVA) }\end{array}$ & $\begin{array}{c}\text { Serve para medir se a } \\
\text { mensagem da administração } \\
\text { tem conteúdo positivo sobre o } \\
\text { desempenho do período }\end{array}$ & $\begin{array}{l}\text { Variável dummy com duas } \\
\text { categorias: mensagem positiva } \\
\text { sobre o desempenho do } \\
\text { período (1) e, mensagem } \\
\text { negativa sobre o desempenho } \\
\text { do período }(0) .\end{array}$ & $\begin{array}{c}\text { Loughran e } \\
\text { MacDonald (2014); } \\
\text { Asay et al. (2017); } \\
\text { Henry e Leone } \\
\text { (2016). }\end{array}$ \\
\hline $\begin{array}{l}\text { Estrutura de Capital } \\
\text { (EST) }\end{array}$ & $\begin{array}{c}\text { Mensura a proporção dos } \\
\text { passivos totais em razão aos } \\
\text { ativos totais }\end{array}$ & $\begin{array}{c}\left(\text { Passivo }_{\text {Total }} \text { /t } / \text { Ativo } \text { Total }_{\mathrm{it}} \text { ) }\right. \\
* 100\end{array}$ & Ertugrul et al., (2017). \\
\hline $\begin{array}{r}\text { Rentabilidade do Ativo } \\
\text { (ROA) }\end{array}$ & $\begin{array}{l}\text { Mensura a rentabilidade diante } \\
\text { dos ativos do fim do período }\end{array}$ & $\begin{array}{c}\text { (Resultado Líquido }{ }_{\mathrm{it}} / \text { Ativo } \\
\left.\text { Total }_{\mathrm{it}}\right) * 100\end{array}$ & $\begin{array}{c}\text { Dempsey et al. } \\
\text { (2012); Souza et al. } \\
\text { (2019). }\end{array}$ \\
\hline \multicolumn{4}{|c|}{ Variáveis Independentes } \\
\hline Variável & Descrição & Operacionalização & Referências \\
\hline $\begin{array}{l}\text { Crescimento da Receita } \\
\text { (CRESCREC) }\end{array}$ & $\begin{array}{l}\text { Mede o aumento/diminuição } \\
\text { da receita em comparação com } \\
\text { o período anual anterior }\end{array}$ & $\begin{array}{c}((\text { Receita Líquida de } \\
\text { Vendas } \\
\left.\left.\text { Vendas }_{\text {it-1 }}\right)-1\right) * 100\end{array}$ & Bloomfield (2008). \\
\hline Tamanho (TAM) & $\begin{array}{l}\text { Apresenta o porte da empresa } \\
\text { por meio dos ativos totais, ao } \\
\text { considerar sua base logarítmica }\end{array}$ & $\begin{array}{c}\text { Logaritmo Natural do Ativo } \\
\text { Total }\end{array}$ & $\begin{array}{l}\text { Habib e Hasan (2018); } \\
\text { Souza et al. (2019). }\end{array}$ \\
\hline
\end{tabular}

Fonte: Elaborado pelos autores (2019).

O índice de legibilidade é dividido em sete categorias de nível de dificuldade: valores entre 90 e 100 (muito fácil); entre 80 e 90 (fácil); entre 70 e 80 (razoavelmente fácil); entre 60 e 70 (padrão); entre 50 e 60 (razoavelmente difícil); entre 30 e 50 (difícil); e entre 0 e 30 (muito difícil) (Flesch, 1948). A partir do cálculo da legibilidade das narrativas do resultado líquido do EBITDA e da mensagem da alta administração, foi possível realizar as análises descritivas (média, desvio-padrão, máximo e mínimo) de todas as variáveis. Como variável dependente do modelo têm-se a legibilidade do resultado líquido, utilizada em pesquisas similares (Subramanian et al., 1993; Kim et al., 2019) e a legibilidade do EBITDA, que se apresenta como um aspecto inovador neste estudo. O EBITDA é utilizado como uma importante ferramenta para tomada de decisão e muito utilizada por investidores e analistas (Frezatti \& Aguiar, 2007; Eastman, 1996; Malvessi, 2006), o que justifica sua utilização. Na Tabela 1 são apresentadas as variáveis deste estudo.

Sobre as variáveis do estudo, não foi considerada a variável "EBITDA Positivo" na análise quantitativa, por não apresentar variabilidade suficiente, já que das 138 observações, apenas uma consistia em EBITDA negativo. Com isso, tal variável não foi considerada no modelo multivariado da legibilidade do EBITDA. Apesar disso, não impediu a análise qualitativa, por meio da análise de conteúdo, quando a companhia registrou EBITDA positivo, em que foi possível analisar casos 
específicos acerca dos enfoques das narrativas textuais sobre o desempenho do período. Com a definição das variáveis utilizadas na análise multivariada, desenvolveu-se os seguintes modelos utilizados para responder o problema de pesquisa:

$$
\begin{aligned}
\text { LEGRE }_{i t}= & \beta_{0}+\beta_{1} \text { RESULPOSITIVO }_{i t}+\beta_{2} \text { ADMPOSITIVA }_{i t}+\beta_{3} \Delta \% \text { RESUL }_{i t}+\beta_{4} \text { EST }_{i t} \\
& +\beta_{5} \text { ROA }_{i t}+\beta_{6} \operatorname{CRESCREC}_{i t}+\beta_{7} \text { TAM }_{i t}+\varepsilon_{i t}
\end{aligned}
$$

$$
\begin{aligned}
& \text { LEGEBITD } A_{i t} \\
& \begin{array}{l}
=\beta_{0}+\beta_{1} \text { ADMPOSITIVA }_{i t}+\beta_{2} \Delta \% E B I T D A_{i t}+\beta_{3} E S T_{i t}+\beta_{4} R O A_{i t} \\
+\beta_{5} \operatorname{CRESCREC}_{i t}+\beta_{6} \text { TAM }_{i t}+\varepsilon_{i t}
\end{array}
\end{aligned}
$$

Onde: LEGRE $_{\mathrm{it}}=$ legibilidade do resultado líquido da empresa i no período t; LEGEBITDA $_{\mathrm{it}}=$ legibilidade do Ebitda da empresa i no período $\mathrm{t}$; RESULPOSITIVO ${ }_{i t}=$ resultado líquido positivo da empresa i no período $\mathrm{t} ; \mathrm{ADMPOSITIVA}_{\mathrm{it}}=$

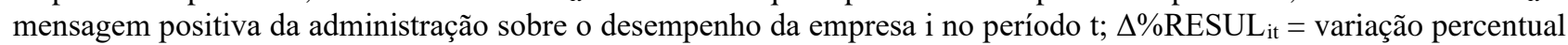
do resultado líquido da empresa i no período $t ; \mathrm{EBITDA}_{\mathrm{it}}=$ variação percentual do EBITDA da empresa i no período $\mathrm{t} ; \mathrm{EST}_{\mathrm{it}}=$ estrutura de capital da empresa i no período $\mathrm{t} ; \mathrm{ROA}_{\mathrm{it}}=$ rentabilidade do ativo da empresa $\mathrm{i}$ no período $\mathrm{t}$; CRESCREC $_{i t}=$ crescimento da receita da empresa i no período t, e; TAM $_{i t}=$ tamanho da empresa i no período $t$.

Esses modelos serviram de base para a análise multivariada de dados em painel. O primeiro passo da análise consistiu em realizar o teste de Chow, de Breusch-Pagan e de Hausman para definir a estimação mais adequada (pooled, efeitos fixos ou efeitos aleatórios) aos dados de cada modelo multivariado. Os resultados desses três testes indicaram que o modelo mais adequado ao modelo apresentado na Equação 2 concerne à estimação por efeitos fixos. Já para o segundo modelo (Equação 3), esses três testes sugerem que os dados se ajustam melhor à estimação por efeitos aleatórios. Os resultados desses testes são expostos na Tabela 4.

Para que as estimações multivariadas (Equação 2 e Equação 3) sejam estimadas de maneira confiável, é necessário que sejam avaliados alguns pressupostos. Dentre eles, tem-se o de multicolinearidade, heterocedasticidade dos resíduos e autocorrelação serial. Os dados foram submetidos ao teste de Spearman (já que as observações não possuem normalidade multivariada, conforme os resultados do teste de Doornik-Hansen) e o teste de Variance Inflation Factor (VIF) para averiguar a existência de multicolinearidade. O teste VIF atestou que não há multicolinearidade entre as variáveis independentes dos dois modelos, já que todos os valores foram inferiores a 5. Isso consiste na ausência de multicolinearidade, como sugerido por Fávero e Belfiore (2017).

A heterocedasticidade dos resíduos foi averiguada por meio do teste de Breusch-Pagan (BP), o qual atestou a inexistência desse problema nos dois modelos multivariados. A autocorrelação serial foi testada por meio do método de Wooldridge (W), específico para dados em painel. Os resultados deste teste, para os dois modelos multivariados, sugerem a inexistência de autocorrelação serial de primeira ordem. Com isso, não foi necessário submeter os dados dos modelos multivariados a qualquer técnica de correção.

\section{RESULTADOS E DISCUSSÕES}

Na Tabela 2 são apresentados os resultados da estatística descritiva das variáveis. Quanto à característica dos desvios-padrão, percebe-se que todas as oito variáveis métricas apresentam característica between (legibilidade do resultado líquido, legibilidade do EBITDA, variação percentual do resultado líquido, variação percentual do EBITDA, estrutura de capital, rentabilidade do ativo, crescimento da receita e tamanho). Com isso, nenhuma das variáveis analisadas apresentou característica whithin. Tais evidências indicam, conforme Fávero (2013), que a estimação de dados em painel mais adequada aos dados confere ao de efeitos aleatórios. 
Tabela 2

Estatística descritiva

\begin{tabular}{|c|c|c|c|c|c|c|c|}
\hline \multirow{2}{*}{ Variáveis } & \multirow{2}{*}{ Média } & \multicolumn{3}{|c|}{ Desvio-Padrão } & \multirow{2}{*}{ Mínimo } & \multirow{2}{*}{ Máximo } & \multirow{2}{*}{ Obs. } \\
\hline & & Overall & Between & Whithin & & & \\
\hline LEGRE & 61,551 & 20,862 & 19,741 & 9,682 & 0 & 100 & 138 \\
\hline LEGEBITDA & 60,848 & 23,878 & 19,100 & 15,102 & 2 & 100 & 138 \\
\hline$\Delta \%$ RESUL & $-18,800$ & 147,075 & 115,885 & 96,888 & $-638,029$ & 449,545 & 138 \\
\hline$\Delta \%$ EBITDA & 7,212 & 39,007 & 28,413 & 3,158 & $-129,153$ & 116,458 & 138 \\
\hline EST & 58,818 & 19,733 & 19,513 & 3,016 & 17,377 & 104,604 & 138 \\
\hline ROA & 3,123 & 4,909 & 4,386 & 1,924 & $-10,528$ & 19,095 & 138 \\
\hline CRESCREC & 9,082 & 18,224 & 15,257 & 12,869 & $-39,051$ & 71,317 & 138 \\
\hline TAM & 15,731 & 1,139 & 1,197 & 0,100 & 13,812 & 19,608 & 138 \\
\hline Variáveis & \multicolumn{2}{|c|}{$\begin{array}{c}n \text { com resultado } \\
\text { positivo/menção positiva } \\
\text { da administração sobre o } \\
\text { desempenho }\end{array}$} & $\begin{array}{l}\text { Frequência } \\
\text { Relativa }(\%)\end{array}$ & \multicolumn{2}{|c|}{$\begin{array}{l}n \text { que não representam } \\
\text { resultado } \\
\text { positivo/menção positiva } \\
\text { da administração sobre o } \\
\text { desempenho }\end{array}$} & $\begin{array}{c}\text { Frequência } \\
\text { Relativa (\%) }\end{array}$ & Obs. \\
\hline RESULPOSITIVO & \multicolumn{2}{|c|}{101} & $73,19 \%$ & \multicolumn{2}{|c|}{37} & $26,81 \%$ & 138 \\
\hline ADMPOSITIVA & \multicolumn{2}{|c|}{109} & $78,99 \%$ & \multicolumn{2}{|c|}{29} & $21,01 \%$ & 138 \\
\hline
\end{tabular}

Legenda: Obs. = observações. LEGRE = legibilidade do resultado líquido; LEGEBITDA = legibilidade do EBITDA; RESULPOSITIVO = resultado líquido positivo; ADMPOSITIVA = mensagem positiva da administração sobre $\mathrm{o}$ desempenho; $\Delta \%$ RESUL = variação percentual do resultado líquido; $\Delta \%$ EBITDA = variação percentual do EBITDA; $\mathrm{EST}=$ estrutura de capital; ROA= rentabilidade do ativo; CRESCREC = crescimento da receita; $\mathrm{TAM}=$ tamanho; $n=$ número de observações.

Fonte: Dados da pesquisa (2019).

Quanto às evidências expostas na Tabela 2, observa-se que, em média, a legibilidade do resultado líquido foi de 61,551. Esse resultado indica que os trechos sobre os resultados obtidos no período são classificados, de acordo com Flesch (1948), como "padrão". Ou seja, as companhias que participam do novo mercado utilizam uma linguagem padrão que pode ser entendida pelos usuários externos da informação contábil, mesmo que não tenham conhecimento dos jargões técnicos. Característica similar foi encontrada quando analisada a legibilidade do EBITDA, uma vez que a pontuação foi de 60,848. A linguagem padrão, sem jargões que dificultam o entendimento do leitor, pode ser justificada a partir da ótica do propósito do RA. Como é um relato geral sobre o que ocorreu na companhia durante o ano, a linguagem "padrão" consegue atingir a maior parte dos investidores, especialmente àqueles que não possuem conhecimentos técnicos aprofundados acerca de procedimentos contábeis ou análise financeira.

Sobre os níveis de facilidade de leitura da variável legibilidade do resultado líquido, salientase que em 9,42\% dos casos o índice de leitura é igual ou acima de 90, representando uma leitura muito fácil. De outra forma, em 12,31\% dos casos houve índice igual ou abaixo de 30, o que pode ser entendido como trechos com narrativas muito difíceis de ler. Quando analisada a legibilidade do EBITDA, nota-se que 9,42\% das observações apresentaram índice acima de 90, enquanto 7,24\% apresentaram índice de legibilidade abaixo de 30.

As empresas apresentaram variação do resultado líquido de $-18,80 \%$, evidência que pode ser justificada pelo período de decréscimo do Produto Interno Bruto (PIB) brasileiro em 2015 e 2016, com variação de $-3,8 \%$ e $-3,6 \%$, respectivamente. Contudo, observa-se que a variação do EBITDA foi de, em média, 7,21\%. Assim, este item referente à atividade operacional teve variação positiva, mesmo em um período com recessão econômica.

Em momento posterior à análise da estatística descritiva, analisou-se a legibilidade do resultado líquido e da legibilidade do EBITDA ao longo do período de análise. Na Figura 1, apresentase o comportamento da legibilidade do resultado líquido e da legibilidade do EBITDA. 

EBITDA

Figura 1

Comportamento da legibilidade do resultado líquido e da legibilidade do EBITDA ao longo do tempo

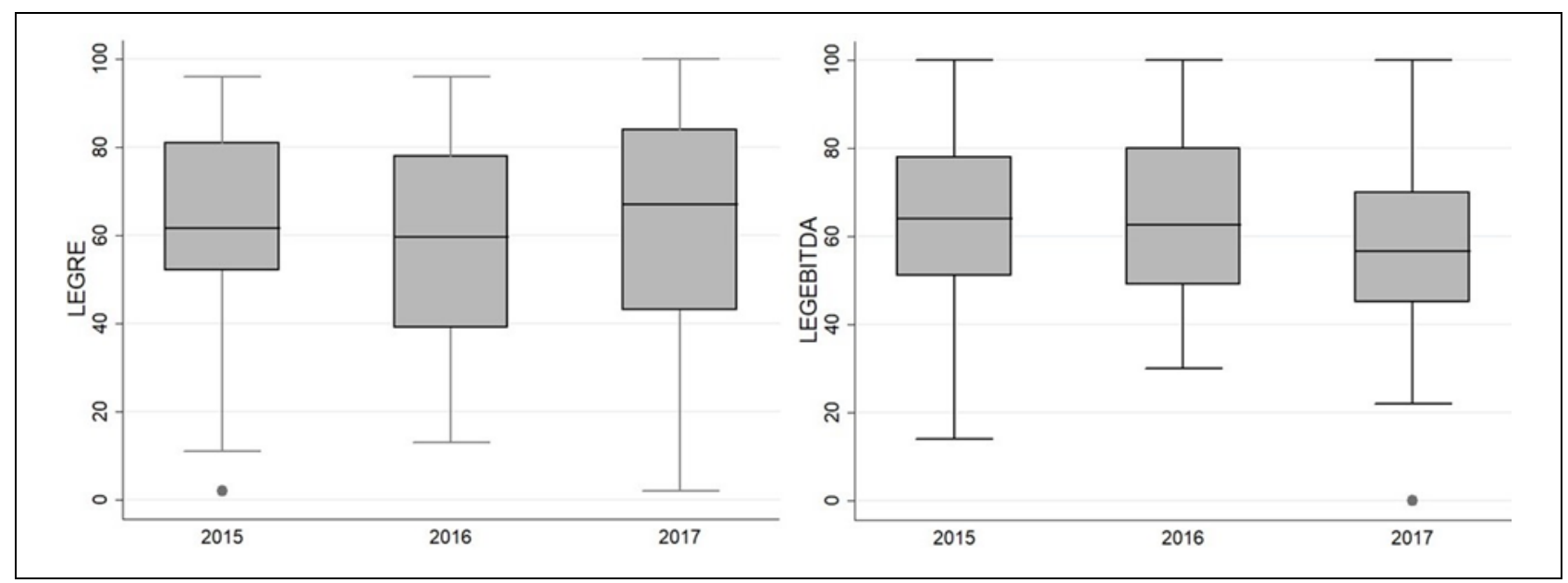

Fonte: Dados da pesquisa (2019).

Ao considerar a análise descritiva da legibilidade do resultado líquido ao longo do tempo, observa-se que em 2015, a legibilidade foi, em média, de 61,95. De acordo com a escala de Flesch (1948), esse valor indica texto padrão (índice de Flesch entre 60 a 70). Ou seja, um texto que é esperado e pode ser entendido pelas pessoas que não necessariamente possuem conhecimentos muito específicos sobre processos contábeis ou partes operacionais da empresa. Isso é importante, pois conhecimentos específicos possuem detalhes com jargões da área que levam à diminuição da legibilidade e, dessa forma, prejudica os usuários com menor nível deste conhecimento.

No ano de 2016 a legibilidade do resultado líquido apresentou decréscimo em comparação com o ano anterior, uma vez que teve índice médio de 58,41, indicando textos que podem ser classificados como "razoavelmente difíceis de ler". Contudo, no ano de 2017 a legibilidade do resultado líquido teve aumento (em comparação aos anos anteriores), com índice médio de 62,17, que na escala de Flesch (1948) indica trechos com leitura "padrão".

Acerca da legibilidade do EBITDA, os achados indicam que em 2015 apresentou média de 63,54, indicando que os trechos nos Relatório de Administração são considerados como de leitura "padrão". Resultado similar também foi encontrado no ano de 2016, já que o nível de legibilidade foi de 63,15. No ano de 2017 o índice de Flesch (1948) apresentou resultado de 57,95, evidência que revela que os trechos de leitura são considerados como "razoavelmente difíceis de ler". Isso mostra que houve uma diminuição na capacidade de clareza no texto, o que pode fazer com que investidores, sobretudo aqueles que possuem menor nível de conhecimento técnico sobre finanças e as operações da empresa, interpretam incorretamente as informações apresentadas.

Para verificar se o nível de legibilidade do resultado líquido e do EBITDA alteraram ao longo do tempo, os dados foram submetidos ao teste de Kruskal-Wallis. Tal teste indicou que não houve variação significativa (Qui-quadrado $=0,983 ; p$-valor $=0,6114$ ) da legibilidade do resultado líquido. O mesmo resultado também foi encontrado para a legibilidade do EBITDA (Qui-quadrado = 1,805; $p$-valor $=0,4053$ ). Esses resultados mostram que, mesmo em períodos com decréscimo da atividade econômica brasileira, os gestores não mudaram significativamente a legibilidade do resultado líquido e do EBITDA, o que pode ser considerado benéfico aos investidores.

A partir das análises da estatística descritiva, recorreu-se à análise qualitativa das narrativas referentes às variáveis utilizadas neste estudo. Observou-se trechos em que havia problemas pragmáticos, haja vista que o transmissor aparentou tentar causar determinado comportamento positivo com base nas narrativas, como no caso da B2W Digital. Nos três períodos analisados apresentou resultados negativos, entretanto, em todo RA não há presença da palavra "prejuízo", em 
contraste, a palavra "lucro" foi descrita, em média, 10 vezes por período. Em complemento, a mensagem do CEO tem caráter positivo, com destaques de recordes quebrados e avanços significativos na organização, seja por vendas ou geração de caixa. Ainda nessa perspectiva, observase a omissão de informações a despeito dos resultados líquidos e EBITDA, o que demonstra ofuscação das mensagens em relação aos resultados de fato obtidos pela organização.

Ao analisar casos extremos da legibilidade (trechos muito fáceis ou muito difíceis de ler, de acordo com o índice de Flesch) das narrativas dos resultados líquidos, os achados apresentam que para trechos de leitura muito fácil, 23,07\% referem-se a prejuízos do exercício. Entretanto, a facilidade de leitura percebida no trecho não traz benefícios aos usuários das informações contábeis, por não apresentarem suplemento aos dados quantitativos. Tais trechos relatam "Encerramos o ano com prejuízo líquido de R\$ milhões", ambos se referem à empresa Santos BRP, dos anos de $2016 \mathrm{e}$ 2015. Por outro lado, ao analisar trechos de leitura muito difícil, este número sobe para 31,25\% das situações.

Quanto à análise das narrativas apresentadas no RA, observou-se que a maioria das empresas obteve EBITDA positivo e, por conta disso, a explicação das narrativas eram práticas e objetivas, como o caso da Magazine Luiza S.A em 2017, no qual o relatório apresenta as seguintes informações:

No 4T17, o EBITDA aumentou 37,8\% para R $\$ 312,7$ milhões, equivalente a uma margem de
$8,6 \%$ (+0,6 p.p. versus o 4T16). O elevado crescimento das vendas, a contribuição positiva
do e-commerce, a diluição das despesas operacionais, bem como a performance da Luizacred
e da Luizaseg, contribuiu para o alcance da maior margem EBITDA para o $4^{\circ}$ trimestre desde
o IPO. Em 2017, o EBITDA cresceu 44,3\% atingindo R $\$ 1.030,8$ milhões, equivalente a uma
margem de $8,6 \%$ (+1,1 p.p. versus 2016$)$.

Percebe-se certa clareza ao apresentar a informação, além da capacidade de argumentação sobre tais resultado. Salienta-se que o resultado líquido desse exercício foi positivo. Dessa forma, a partir dos resultados satisfatórios, é possível inferir que o contexto é propício para apresentar informações de fácil leitura e entendimento. Por esta razão, a legibilidade do EBITDA da Magazine Luiza S.A em 2017 foi classificada como de razoável entendimento, obtendo um nível de leitura de 69 pontos no índice de Flesch. Casos similares ocorreram em outras empresas da amostra (Natura 2015, Valid 2015, Movida 2016, JBS 2016 e Linx 2017) com EBITDA e resultado líquido positivos, as quais apresentaram maior legibilidade das narrativas do EBITDA.

No entanto, em situações opostas, assim que os resultados líquidos não davam respaldo ao valor do EBITDA e vice-versa, observou-se que o grau de complexidade da legibilidade das narrativas sobre o EBITDA se tornava maior. Por exemplo, a Profarma, no exercício de 2017, apresentou uma narrativa do EBITDA de difícil entendimento, equivalente a 26 pontos, segundo o índice de Flesch, como se pode observar:

O EBITDA consolidado da Companhia atingiu R \$ 59,2 milhões, R \$ 64,7 milhões menor, na comparação com o ano anterior, sendo $86 \%$ relacionado a dois principais eventos: (i) o aumento de preços ocorrido em 2017 (médio de 3,5\%), 70\% menor que o reajuste de 2016 (médio de 11,5\%), responsável por $80 \%$ da redução; e (ii) a absorção do EBITDA negativo da Rede Rosário de um ano completo" apesar de apresentar um texto curto, no entanto a maneira como justifica o EBITDA torna-se difícil de entender.

Quanto à análise dos trechos das mensagens da administração, percebe-se o foco do desempenho positivo da organização, muito embora diversas empresas apontaram resultados líquidos negativos. Dentre todas as empresas que foram analisadas no período de 2015 a 2017 , em 138 ocasiões a mensagem tinha cunho positivo (78,98\% das observações). Quando houve menção positiva ao desempenho, destaca-se que em 76,14\% dos casos a empresa apresentou resultado líquido positivo. De modo a exemplificar, a Suzano Papel, em 2015, apresentou um aumento em seu prejuízo no montante de $\mathrm{R} \$ 663,9$ milhões em relação a 2014, o que totalizou um prejuízo de $\mathrm{R} \$$ 925,4 milhões. 
Mesmo com tais resultados líquidos, a mensagem da administração teve enfoque no recorde de receita e EBITDA:

O último ano foi marcado por fortes resultados operacionais e financeiros. Foram registrados receita líquida e EBITDA ajustado recorde em 2015, totalizando, respectivamente, $\mathrm{R} \$ 10,22$ bilhões (+41\% vs 2014) e R 4,59 bilhões (+87\% vs 2014), e reduzimos a alavancagem para 2,7x dívida líquida/EBITDA ajustado ao final de 2015 (vs 4,1x em dezembro de 2014).

Tal distorção do enfoque da mensagem da administração quanto ao desempenho financeiro e econômico também é percebida em relação ao EBITDA, como na Direcional 2016, que teve uma queda neste indicador de 66\%, mas a mensagem da administração focou na receita da organização:

Analisando agora o Resultado Financeiro, a receita bruta de venda de imóveis, já impulsionada pela a evolução do segmento MCMV 2 e 3, atingiu R\$ 157 milhões no 4T16 e $\mathrm{R} \$ 661$ milhões em 2016, crescimento de $21 \%$ em relação ao trimestre anterior e $10 \%$ em relação ao ano anterior. Com isso, o segmento de incorporação foi responsável por 59\% da receita bruta total apropriada no trimestre e $46 \%$ em 2016.

Embora haja apontamentos de situações de distorção da realidade apresentada pela organização, há também a demonstração da realidade da situação econômico-financeira por parte da mensagem da administração, como no caso da Natura em 2015, que apesar de ter atingido um Resultado Líquido de R \$ 513 milhões, apresentou a seguinte percepção sobre seu desempenho: "Obtivemos um resultado aquém de nossas expectativas e possibilidades. Diante dessas forças distintas, alcançamos uma receita líquida consolidada de $\mathrm{R} \$ 7,9$ bilhões, com EBITDA de R\$ 1,5 bilhão e lucro líquido de R\$ 513 milhões”.

Tabela 3

Matriz de correlação de Spearman

\begin{tabular}{|c|c|c|c|c|c|}
\hline Variáveis & LEGRE & $\begin{array}{c}\text { LEG } \\
\text { EBITDA }\end{array}$ & $\begin{array}{c}\text { RESUL } \\
\text { POSITIVO }\end{array}$ & $\begin{array}{c}\text { ADM } \\
\text { POSITIVA }\end{array}$ & $\begin{array}{c}\Delta \% \\
\text { RESUL }\end{array}$ \\
\hline LEGRE & 1 & & & & \\
\hline LEGEBITDA & $0,28 * * *$ & 1 & & & \\
\hline RESULPOSITIVO & $0,17 * *$ & 0,14 & 1 & & \\
\hline ADMPOSITIVA & 0,12 & 0,13 & 0,13 & 1 & \\
\hline$\Delta \%$ RESUL & $-0,07$ & $-0,04$ & $0,18 * *$ & 0,06 & 1 \\
\hline$\Delta \%$ EBITDA & $0,17 * *$ & $-0,01$ & $0,25 * * *$ & 0,06 & $0,37 * * *$ \\
\hline EST & $-0,07$ & $-0,01$ & $-0,34 * * *$ & $-0,05$ & $-0,18 * *$ \\
\hline ROA & 0,08 & 0,04 & $0,76^{* * *}$ & 0,11 & $0,34 * * *$ \\
\hline CRESCREC & 0,09 & $-0,01$ & $0,25 * * *$ & 0,06 & $0,29 * * *$ \\
\hline TAM & $-0,01$ & $-0,08$ & 0,02 & $0,25 * * *$ & $0,14 *$ \\
\hline Variáveis & $\begin{array}{c}\Delta \% \\
\text { EBITDA }\end{array}$ & EST & ROA & CRESCREC & TAM \\
\hline$\Delta \%$ EBITDA & 1 & & & & \\
\hline EST & $-0,03$ & 1 & & & \\
\hline ROA & $0,22 * * *$ & $-0,53 * * *$ & 1 & & \\
\hline CRESCREC & $0,58 * * *$ & $-0,01$ & $0,21 * *$ & 1 & \\
\hline TAM & 0,09 & $0,34 * * *$ & $-0,02$ & $-0,07$ & 1 \\
\hline
\end{tabular}

Legenda: *significância ao nível de 10\%; ** significância ao nível de 5\%, e; ***significância ao nível de $1 \%$ ao considerar análise bicaudal. LEGRE = legibilidade do resultado líquido; LEGEBITDA = legibilidade do EBITDA; RESULPOSITIVO = resultado líquido positivo; ADMPOSITIVA = mensagem positiva da administração sobre o desempenho; $\Delta \%$ RESUL = variação percentual do resultado líquido; $\Delta \%$ EBITDA = variação percentual do EBITDA; $\mathrm{EST}=$ estrutura de capital; $\mathrm{ROA}=$ rentabilidade do ativo; $\mathrm{CRESCREC}=$ crescimento da receita; $\mathrm{TAM}=$ tamanho. Fonte: Dados da pesquisa (2019). 
A partir da análise de conteúdo das narrativas, realizou-se a análise de correlação de Spearman. Os resultados são apresentados na Tabela 3, que apresentam que o coeficiente de correlação entre a legibilidade do resultado líquido e a legibilidade do EBITDA foi de 0,28 . Isso pode ser justificado devido ao fato de que se referem a itens sobre o desempenho econômico-financeiro. Com isso, quando o EBITDA é positivo, geralmente, há também resultado positivo no resultado líquido.

Ao analisar as variáveis independentes, verifica-se que o maior coeficiente de correlação é entre as variáveis resultado líquido positivo e rentabilidade do ativo, com 0,76 . Portanto, todos os coeficientes de correlação entre as variáveis independentes são abaixo de 0,80 . Isso indica que não há indícios de multicolinearidade nos modelos multivariados, como sugerido por Gujarati e Porter (2011). De modo complementar, realizou-se o teste VIF, com a finalidade de verificar a existência de multicolinearidade entre as variáveis independentes do modelo multivariado da legibilidade do resultado líquido e da legibilidade do EBITDA. Os resultados revelam que todos os valores estão abaixo de 5, o que demonstra que os modelos não apresentam variáveis independentes multicolineares, como sugerido por Fávero e Belfiore (2017).

Tabela 4

Análise multivariada da Legibilidade do Resultado Líquido e EBITDA

\begin{tabular}{|c|c|c|c|c|}
\hline \multicolumn{5}{|c|}{ Painel A: Modelos multivariados } \\
\hline \multirow{3}{*}{ Variável } & \multicolumn{2}{|c|}{ LEGRE } & \multicolumn{2}{|c|}{ LEGEBITDA } \\
\hline & \multicolumn{2}{|c|}{ Modelo 1} & \multicolumn{2}{|c|}{ Modelo 2} \\
\hline & Coef. & Estat T & Coef. & Estat T \\
\hline RESULPOSITIVO & 12,0883 & 1,32 & & \\
\hline ADMPOSITIVA & $-0,0791$ & $-0,01$ & 7,5569 & $1,88^{*}$ \\
\hline$\Delta \%$ RESUL & $-0,0100$ & $-0,59$ & & \\
\hline$\Delta \%$ EBITDA & & & 0,0292 & 0,75 \\
\hline EST & $-1,7866$ & $-3,18 * * *$ & 0,0839 & 0,56 \\
\hline ROA & $-0,1169$ & $-0,10$ & 0,0968 & 0,20 \\
\hline CRESCREC & 0,1492 & 1,14 & $-0,1118$ & $-1,28$ \\
\hline TAM & 38,1846 & $2,23 * *$ & $-3,4228$ & $-1,47$ \\
\hline Constante & $-444,7259$ & $-1,68$ & 105,3401 & $3,02 * * *$ \\
\hline $\mathrm{R} 2$ & \multicolumn{2}{|c|}{0,21} & \multicolumn{2}{|c|}{0,02} \\
\hline Estatística F/Wald & \multicolumn{2}{|c|}{$2,74 * *$} & \multicolumn{2}{|c|}{$6,63 * * *$} \\
\hline Observações & \multicolumn{2}{|c|}{138} & \multicolumn{2}{|c|}{138} \\
\hline
\end{tabular}

Observações

Painel B: Pressupostos da análise multivariada

\begin{tabular}{lcccc}
\hline Testes & Chi2/Estat F & p-valor & Chi2/Estat F & p-valor \\
\hline Breusch-Pagan & 0,14 & 0,703 & 0,32 & 0,571 \\
Wooldridge & 0,02 & 0,876 & 0,68 & 0,416 \\
VIF & & 1,62 & & 1,45 \\
\hline
\end{tabular}

Painel C: Testes para escolha da estimação mais adequada aos dados

\begin{tabular}{lcccc}
\hline Testes & Chi2/Estat F & p-valor & Chi2/Estat F & p-valor \\
\hline Chow & 2,41 & 0,000 & 4,73 & 0,000 \\
L. M. Breusch-Pagan & 9,77 & 0,001 & 24,33 & 0,000 \\
Hausman & 15,62 & 0,028 & 2,23 & 0,8976 \\
\hline
\end{tabular}

Legenda: *significância ao nível de 10\%; ** significância ao nível de 5\%, e; ***significância ao nível de 1\%. A regressão referente ao Modelo 1 foi estimada por meio da técnica de dados em painel por efeitos fixos. O Modelo 2 foi estimado por meio da técnica de dados em painel por efeitos aleatórios. LEGRE = legibilidade do resultado líquido; LEGEBITDA = legibilidade do EBITDA; RESULPOSITIVO = resultado líquido positivo; ADMPOSITIVA = mensagem positiva da administração sobre o desempenho; $\Delta \%$ RESUL = variação percentual do resultado líquido; $\Delta \% \mathrm{EBITDA}=$ variação percentual do EBITDA; EST = estrutura de capital; ROA= rentabilidade do ativo; $\mathrm{CRESCREC}=$ crescimento da receita; TAM $=$ tamanho.

Fonte: Dados da pesquisa (2019). 
Em momento posterior, com o propósito de averiguar os pressupostos de heterocedasticidade e autocorrelação serial, realizou-se os testes de Breusch-Pagan (BP) e Wooldridge (W), respectivamente. $\mathrm{O}$ teste de $\mathrm{BP}$ sugere que os dois modelos multivariados apresentam homocedasticidade dos resíduos. Já o teste de $\mathrm{W}$ indicou que os dados dos dois modelos multivariados não apresentam problema de autocorrelação serial de primeira ordem. Por esse motivo, não foi necessário fazer quaisquer correções na estimação dos dois modelos.

Assim, os dados foram submetidos à análise de dados em painel por meio de dois modelos multivariados. O primeiro, com o objetivo de analisar os fatores relacionados à legibilidade do resultado líquido (Modelo 1), e o segundo, para verificar os fatores relacionados à legibilidade do EBITDA (Modelo 2). Os resultados desses modelos são apresentados na Tabela 4.

Os achados do Modelo 1 evidenciam que o resultado líquido positivo não está associado à legibilidade do resultado líquido, o que diverge de pesquisas sobre o tema, como a de Subramanian et al. (1993). O resultado da presente pesquisa pode ser entendido como um aspecto positivo para os usuários externos, especialmente quanto ao processo decisório, uma vez que os gestores não ofuscam o conteúdo do relatório de administração a depender do desempenho econômico-financeiro compreender um lucro ou prejuízo.

Em relação à menção positiva da administração sobre o desempenho, nota-se que não está associada à legibilidade do resultado líquido. Esse resultado também pode ser considerado como benéfico para os investidores, uma vez que a menção positiva do lucro líquido no período não é um fator que interfere no nível de legibilidade dos trechos a respeito do resultado líquido do período.

A variação percentual do resultado líquido não está relacionada com a legibilidade do resultado líquido. Esse resultado difere do estudo de Kim et al. (2019), que apontou relação positiva entre o desempenho financeiro com o nível de legibilidade das informações financeiras. O resultado apresentado na Tabela 4 mostra que os gestores não ofuscam as informações a partir de frases menos legíveis, mesmo quando há variação negativa do resultado líquido em relação ao ano anterior. Essas evidências sugerem possível benefício aos investidores e analistas, uma vez que em períodos de queda significativa do resultado líquido, os gestores não alteram a forma com que as informações são apresentadas para manipular a percepção do mercado a respeito da companhia.

No que concerne às variáveis de controle, a estrutura de capital da empresa está negativamente relacionada à legibilidade do resultado líquido, o que está de acordo com os resultados de Ertugrul et al. (2017). Assim, à medida que as empresas se tornam mais endividadas, os gestores publicam relatórios com menores níveis de legibilidade acerca do resultado líquido do período. A respeito da rentabilidade do ativo, nota-se que não está relacionada à legibilidade do resultado líquido, achado diferente do encontrado por Souza et al. (2019). No que tange ao crescimento da receita, os resultados sugerem que não exerce influência na legibilidade do resultado líquido, contrário do tratado por Bloomfield (2008), que comenta que a variação da receita influencia no nível da legibilidade de trechos referentes aos lucros.

Outro resultado confere à relação positiva e significativa entre o tamanho e a legibilidade do resultado líquido, o que corrobora Souza et al. (2019). Essa ocorrência justifica-se devido à necessidade das empresas de maior porte proporcionarem relatórios com maiores níveis de qualidade aos usuários externos da informação contábil. Infere-se que a pressão dos investidores contribui para esta postura organizacional, além de que as empresas maiores despertam cada vez mais a atenção.

Em relação ao Modelo 2 (legibilidade do EBITDA), constata-se que a mensagem positiva da administração sobre o desempenho apresentou relação positiva com a legibilidade do EBITDA. Denota-se conformidade com o descrito por Henry e Leone (2016), por elencarem que os comentários positivos dos gestores acerca do desempenho econômico-financeiro do período resultam em narrativas de itens do desempenho econômico-financeiro com maior nível de legibilidade. Com isso, infere-se que os gestores ofuscam os trechos referentes ao EBITDA do período quando não apresentam viés positivo a respeito do desempenho. Isso pode ser considerado prejudicial aos investidores, já que podem ser induzidos a entenderem de melhor forma as informações sobre o 
EBITDA apenas quando a administração faz referência positiva ao desempenho alcançado no período.

Os resultados também ilustram que a variação percentual do EBITDA não está relacionada com a legibilidade do EBITDA. Observa-se, com isso, discordância com a pesquisa de Kim et al. (2019), visto que estes apontam relação entre o desempenho financeiro e a legibilidade dos relatórios financeiros. Isso mostra que, mesmo com variação positiva ou negativa, os gestores não aumentam ou diminuem propositalmente a legibilidade dos trechos do EBITDA, para alterar a percepção do mercado devido a propósitos particulares. Assim, os investidores são beneficiados, já que não precisam se preocupar a respeito dos trechos sobre o EBITDA, mesmo em períodos em que houve diminuição significativa desse item de resultado do período, que trata sobre as operações da companhia.

A respeito das variáveis de controle, percebe-se que a legibilidade do EBITDA também não está associada com a estrutura de capital, o que vai de encontro com a literatura sobre o tema, como por exemplo, o estudo de Ertugrul et al. (2017). De modo semelhante, não foi encontrada relação significativa entre a legibilidade do EBITDA e a rentabilidade do ativo, diferente do apontado por Dempsey et al. (2012), que sugeriram que a rentabilidade do ativo ofuscava a legibilidade do EBITDA. O crescimento da receita não está relacionado com a legibilidade do EBITDA, o que pode interessar a usuários externos da informação financeira, já que a variação nesse índice referente à mudança proporcional no valor de receita líquida obtida no período, não é motivo para que os gestores tornem os trechos sobre o EBITDA menos legíveis. O tamanho não está relacionado à legibilidade do EBITDA, o que está em desacordo com o descrito por Habib e Hasan (2018) e Souza et al. (2019). Assim, percebe-se que os gestores das companhias de diferentes portes mantêm o mesmo nível de legibilidade dos trechos referentes ao EBITDA no RA.

\section{CONSIDERAÇÕES FINAIS}

A pesquisa teve como objetivo analisar a influência do desempenho econômico-financeiro na legibilidade das narrativas textuais dos trechos de Resultado Líquido e EBITDA. Ao analisar as narrativas textuais do resultado líquido, percebeu-se que algumas companhias apresentam trechos razoavelmente difíceis de ler, segundo índice de Flesch. As companhias que apresentaram resultado líquido negativo enfatizam em menor número a palavra "prejuízo" em relação à palavra "lucro". Isso pode ser uma forma de amenizar os resultados ruins da organização para os usuários externos. Assim, o foco da atenção da mensagem da administração, em muitos dos casos, foi enviesada para aspectos positivos, para realçar a evolução organizacional, de modo a omitir resultados negativos ou inferiores ao esperado.

Os achados desta pesquisa geram implicações para os investidores, uma vez que apontam que a forma como os gestores mencionam o desempenho da empresa, pode persuadir os usuários externos na escolha de determinada alternativa de investimento. Apesar disso, há exceções, dado que algumas companhias não ofuscam seus relatórios diante de resultado não satisfatório, o que é benéfico ao investidor e demonstra o comprometimento dos gestores. Os resultados da análise quantitativa indicam que quando a administração possui uma mensagem positiva acerca do desempenho do período, há aumento da legibilidade do EBITDA, mas não há relação com a legibilidade do resultado líquido. Esse resultado indica que os gestores enxergam o EBITDA como uma informação importante para os investidores, uma vez que tendem a mudar o nível de complexidade da informação escrita à medida que destacam pontos positivos sobre o que pode diminuir a capacidade de entendimento dos investidores quanto à análise dos resultados do EBITDA, sobretudo àqueles que não possuem conhecimentos mais aprofundados de contabilidade e utilizam o relatório de administração como um dos principais relatórios para desempenho do período.

Por outro lado, destaca-se que a inserção de menções positivas sobre o desempenho do período não impacta a legibilidade do resultado do período, logo, torna-se benéfico aos investidores, porque 
pode implicar na inexistência de gerenciamento de impressão. Essas evidências têm implicações práticas aos usuários externos, dado que o não reflexo na legibilidade das narrativas textuais, independentemente se o resultado líquido do período foi positivo ou negativo, é benéfico porque os investidores não serão prejudicados com informações textuais de menor qualidade.

Este estudo apresenta limitações, como os meios utilizados para realização dos testes de legibilidade, pois outros índices podem ser utilizados. Outra limitação consiste na amostra utilizada, uma vez que foi não probabilística, logo, não se pode generalizar as evidências desta pesquisa para empresas de outros países, além de limitar ao escopo de análise (amostra selecionada). Como sugestões de pesquisa, tem-se a variabilidade de legibilidade entre as seções dos relatórios contábeis. Outra sugestão de pesquisa seria analisar a legibilidade com a qualidade da informação contábil, bem como examinar a legibilidade das narrativas de hedge. Além disso, pode-se explorar a realização de pesquisas relacionadas à legibilidade com empresas de diferentes países, como por exemplo, países de língua portuguesa para seguir o mesmo padrão de idioma.

\section{AGRADECIMENTOS}

O presente trabalho foi realizado com apoio da Coordenação de Aperfeiçoamento de Pessoal de Nível Superior - Brasil (CAPES) - Código de Financiamento 001.

\section{REFERÊNCIAS}

Araújo, C. A. Á. (2009). Correntes teóricas da ciência da informação. Ciência da Informação, 38(3), 192204.

Asay, H. S., Elliott, W. B., \& Rennekamp, K. (2017). Disclosure readability and the sensitivity of investors' valuation judgments to outside information. The Accounting Review, 92(4), 1-25.

Bardin, L. (1995). Análise de conteúdo. Lisboa: Persona.

Bloomfield, R. J. (2002). The incomplete revelation hypothesis' and financial reporting. Accounting Horizons, 16(3), 233-243.

Bloomfield, R. (2008). Discussion of "annual report readability, current earnings, and earnings persistence". Journal of Accounting and Economics, 45(2-3), 248-252.

Bonsall, S. B., \& Miller, B. P. (2017). The impact of narrative disclosure readability on bond ratings and the cost of debt. Review of Accounting Studies, 22(2), 608-643.

Brasil Bolsa Balcão - B3 (2018). Segmentos de listagem: Novo Mercado. http://www.bmfbovespa.com.br/pt_br/listagem/acoes/segmentos-de-listagem/novo-mercado/.

Brasil (1976). Lei n. 6404, de 15 de dezembro de 1976. Dispõe sobre as Sociedades por Ações. Diário Oficial da União. Brasília.

Cazier, R. A., \& Pfeiffer, R. J. (2016). Why are 10-K filings so long?. Accounting Horizons, 30(1), 1-21.

Colauto, R. D., \& Marques, V. A. (2010). Influência do discurso otimista do relatório de administração no valor de mercado de companhias brasileiras. Revista Contabilidade e Controladoria, 2(1).

Comissão de Valores Mobiliários (1987). Parecer de Orientação CVM 15. Data de acesso: 18 mar. 2019. Disponível em: http://www.cvm.gov.br/legislacao/pareceres-orientacao/pare015.html.'

Dempsey, S. J., Harrison, D. M., Luchtenberg, K. F., \& Seiler, M. J. (2012). Financial opacity and firm performance: the readability of REIT annual reports. The Journal of Real Estate Finance and Economics, 45(2), 450-470.

Doná, A. L., Marques, K. C. M., Moribe, A. M., \& Hercos Jr., J. B. H. (2015). Fatores determinantes do conteúdo divulgado no relatório de administração de empresas brasileiras. Revista Universo Contábil, 11(4), 82-106.

Dye, R. A. (2001). An evaluation of "essays on disclosure" and the disclosure literature in accounting. Journal of Accounting and Economics, 32(1-3), 181-235.

Eastman, K. (1996). EBITDA: an overrated tool for cash flow analysis. Com. Lending Rev., 12, 64.

Ertugrul, M., Lei, J., Qiu, J., \& Wan, C. (2017). Annual report readability, tone ambiguity, and the cost of borrowing. Journal of Financial and Quantitative Analysis, 52(2), 811-836.

Fávero, L. P. L. (2013). Dados em painel em contabilidade e finanças: teoria e aplicação. BBR-Brazilian Business Review, 10(1), 131-156. 
Fávero, L. P., \& Belfiore, P. (2017). Manual de análise de dados: estatística e modelagem multivariada com Excel®, SPSS® e Stata ${ }^{\circledR}$. Elsevier Brasil.

Flesch, R. (1948). A new readability yardstick. Journal of Applied Psychology, 32(3), 221.

Frezatti, F., \& de Aguiar, A. B. (2007). EBITDA: possíveis impactos sobre o gerenciamento das empresas. Revista Universo Contábil, 3(3), 07-24.

Gomes, M. C, Ferreira, R. R., \& Martins, V. A. (2019). O impacto da OCPC 07 sobre o tamanho e a legibilidade das notas explicativas de companhias brasileiras. Revista Universo Contábil, 14(2), 162184.

Greenberg, H. (1998). Ebitda: Never trust anything that you can't pronounce. Fortune, 137(12), 192193.

Gujarati, D. N. \& Porter, D. C. (2011). Basic econometrics-5. Amgh Editora.

Hadi, A. S. (1992). Identifying multiple outliers in multivariate data. Journal of the Royal Statistical Society: Series B (Methodological), 54(3), 761-771.

Habib, A., \& Hasan, M. M. (2018). Business strategies and annual report readability. Accounting \& Finance, 60(1), 2513-2547.

Healy, P. (1977). Can you understand the footnotes to financial statements. Accountants Journal, 56(July), 219-222.

Hendriksen, E. \& Van Breda, M. F. (2007). Teoria da contabilidade. 5 ed. São Paulo: Atlas.

Henry, E., \& Leone, A. J. (2016). Measuring qualitative information in capital markets research: Comparison of alternative methodologies to measure disclosure tone. The Accounting Review, 91(1), 153-178.

Inger, K. K., Meckfessel, M. D., Zhou, M., \& Fan, W. (2018). An examination of the impact of tax avoidance on the readability of tax footnotes. The Journal of the American Taxation Association, 40(1), 1-29.

Inger, K. K. (2014). Relative valuation of alternative methods of tax avoidance. The Journal of the American Taxation Association, 36(1), 27-55.

Jones, M. J., \& Shoemaker, P. A. (1994). Accounting narratives: A review of empirical studies of content and readability. Journal of Accounting Literature, 13, 142.

Kim, C., Wang, K., \& Zhang, L. (2019). Readability of 10-K reports and stock price crash risk. Contemporary Accounting Research, 36(2), 1184-1216.

Kos, S. R., Espejo, M. M. D. S. B., \& Raifur, L. (2014). O conteúdo informacional do relatório da administração e o desempenho das empresas brasileiras do Ibovespa. Revista Universo Contábil, 10(2), 43-62.

Laksmana, I., Tietz, W., \& Yang, Y. W. (2012). Compensation discussion and analysis (CD\&A): Readability and management obfuscation. Journal of Accounting and Public Policy, 31(2), 185-203.

Law, K. K., \& Mills, L. F. (2015). Taxes and financial constraints: Evidence from linguistic cues. Journal of Accounting Research, 53(4), 777-819.

Lebar, M. A. (1982). A general semantics analysis of selected sections of the $10-\mathrm{K}$, the annual report to shareholders, and the financial press release. The Accounting Review, 57(1), 176-189.

Lee, Y. J. (2012). The effect of quarterly report readability on information efficiency of stock prices. Contemporary Accounting Research, 29(4), 1137-1170.

Li, F. (2008). Annual report readability, current earnings, and earnings persistence. Journal of Accounting and Economics, 45(2-3), 221-247.

Li, F. (2010). The information content of forward-looking statements in corporate filings-A naïve Bayesian machine learning approach. Journal of Accounting Research, 48(5), 1049-1102.

Lim, E. K., Chalmers, K., \& Hanlon, D. (2018). The influence of business strategy on annual report readability. Journal of Accounting and Public Policy, 37(1), 65-81.

Lo, K., Ramos, F., \& Rogo, R. (2017). Earnings management and annual report readability. Journal of Accounting and Economics, 63(1), 1-25.

Loughran, T., \& McDonald, B. (2014). Measuring readability in financial disclosures. The Journal of Finance, 69(4), 1643-1671.

Malvessi, O. (2006). É o EBITDA um bom indicador para a gestão financeira, e útil para a remuneração variável nas empresas?. Revista IBEFNews-SP, Dez. 2006, 30-31

Merkl-Davies, D. M., \& Brennan, N. (2007). Discretionary disclosure strategies in corporate narratives: incremental information or impression management?. Journal of Accounting Literature, 26, 116-196. 
Miller, B. P. (2010). The effects of reporting complexity on small and large investor trading. The Accounting Review, 85(6), 2107-2143.

Miranda, I. A.; Reina, D.; Lemes, S. (2018, julho). Grau de legibilidade dos relatórios financeiros em empresas do novo mercado. Anais do XVIII USP International Conference in Accounting, São Paulo, SP.

Simone, L., Mills, L. F., \& Stomberg, B. (2014, January). What does income mobility reveal about the tax risk-reward tradeoff?. Proceedings of Annual Conference on Taxation and Minutes of the Annual Meeting of the National Tax Association (Vol. 107). National Tax Association.

Smith, J. E., \& Smith, N. P. (1971). Readability: A measure of the performance of the communication function of financial reporting. The Accounting Review, 46(3), 552-561.

Souza, J. A. S., Rissatti, J. C., Rover, S., \& Borba, J. A. (2019). The linguistic complexities of narrative accounting disclosure on financial statements: An analysis based on readability characteristics. Research in International Business and Finance, 48, 59-74.

Souza, L. D. M., \& Silva, C. A. T. (2016). Similarity of management reports of Brazilian firms. International Journal of Multivariate Data Analysis, 1(1), 43-60.

Subramanian, R., Insley, R. G., \& Blackwell, R. D. (1993). Performance and readability: A comparison of annual reports of profitable and unprofitable corporations. The Journal of Business Communication (1973), 30(1), 49-61.

Tschopp, D., Barney, D., \& Dean, P. C. (2018). The readability of financial statement note disclosures. International Journal of Business, Accounting, \& Finance, 12(1), 63-74.

Vasconcelos, Y. L. (2001). EBITDA redescoberta do potencial informativo dos indicadores absolutos. Revista do Conselho Regional do Rio Grande do Sul. Porto Alegre, (102), 1-9.

Williamson, J. M. L., \& Martin, A. G. (2010). Analysis of patient information leaflets provided by a district general hospital by the Flesch and Flesch-Kincaid method. International Journal of Clinical Practice, 64(13), 1824-1831.

Xu, Q., Fernando, G. D., \& Tam, K. (2018). Executive age and the readability of financial reports. Advances in Accounting, 43, 70-81.

You, H., \& Zhang, X. J. (2009). Financial reporting complexity and investor underreaction to 10-K information. Review of Accounting Studies, 14(4), 559-586. 